\title{
Multisystem Inflammatory Syndrome in Children Associated with COVID 19 Treated with Oral Steroid
}

\author{
Mukesh Kumar Jain ${ }^{1}$ - Sanjay Kumar Sahu ${ }^{1}$ - Jyoti Ranjan Behera ${ }^{1}$ (D) - Sibabratta Patnaik ${ }^{1}$
}

Received: 3 August 2020 / Accepted: 10 September 2020 / Published online: 15 September 2020

(C) Dr. K C Chaudhuri Foundation 2020

To the Editor: Multisystem inflammatory syndrome in children (MIS-C) have been reported from various parts of the globe including India sharing clinical features with Kawasaki disease (KD) and toxic shock syndrome (TSS) [1]. World Health Organisation (WHO) and Centre for Disease Control and Prevention (CDC) have laid down case defining criteria for MIS-C separately [2, 3]. Antibody dependent enhancement (ADE) is the proposed pathogenesis leading to cytokine storm. Intravenous immunoglobulin (IVIG) with or without aspirin and Methyl prednisolone are being advocated for its management [4]. Here we report a case of MIS-C managed by oral steroid only with complete recovery.

A 3-y-old male presented with fever and urticarial rashes for $4 \mathrm{~d}$, loose stool for $2 \mathrm{~d}$ with facial puffiness, non purulent bilateral bulbar conjunctivitis and edema of hands and feet. Vitals and systemic examinations were normal. He was admitted as a case of urticaria with angioedema keeping scrub typhus, KD as other differential diagnosis. There was neutrophilic leukocytosis with lymphopenia, normal eosinophils, thrombocytosis and high ESR. Biochemical investigations revealed C-reactive protein $192 \mathrm{mg} / \mathrm{dl}$ (Normal <6), serum sodium $121 \mathrm{mmol} / \mathrm{L}$ (Normal-135-145), serum albumin $2.4 \mathrm{~g} / \mathrm{dl}$ (Normal: 4-6) with normal liver and renal function. Echocardiography was normal. Scrub serology was negative. He was managed with antibiotics, antihistaminics, antipyretics and oral prednisolone at $1 \mathrm{mg} / \mathrm{kg}$ in 2 divided doses. Urine culture and blood culture were sterile.

In view of the ongoing pandemic and features suggesting MIS-C, RT-PCR was sent which was positive for SARS CoV2. D-dimer was high with normal ferritin. Hence diagnosed as MIS-C, meeting all 6 WHO criteria [2]. By the time

Jyoti Ranjan Behera

dr.jyoti2011@gmail.com

1 Department of Pediatrics, Kalinga Institute of Medical Sciences, KIIT University, Bhubaneswar 751024, Odisha, India diagnosis was made, child had dramatic clinical improvement. Hence oral steroid was continued. Inflammatory and biochemical parameters normalized on day 5. Child was discharged on day 7 with oral steroid for 2 wks.

As the pandemic is growing exponentially, all pediatricians should be aware of MIS-C, which will help in prompt diagnosis and management. Treatment options are IVIG, intravenous steroids and biologics like tocilizumab among which IVIG being the preferred one. Oral steroids may be considered as a treatment option in milder forms (without features of shock or cardiac involvement) but require more extensive trials before recommendation.

\section{Compliance with Ethical Standards}

Conflict of Interest None.

\section{References}

1. Rauf A, Vijayan A, John ST, et al. Multisystem inflammatory syndrome with features of atypical kawasaki disease during COVID-19 pandemic. Indian J Pediatr. 2020. https://doi.org/10.1007/s12098020-03357-1.

2. Multisystem inflammatory syndrome in children and adolescents with COVID-19. Scientific brief: World Health Organisation. Available at: https://www.who.int/publications-detail/multisysteminflammatory-syndrome-in-children-andadolescents-with-covid-19. Accessed 15 May 2020.

3. Centers for Disease Control and Prevention. Emergency preparedness and response: Health alert network. Available at: https:// emergency.cdc.gov/han/2020/han00432.asp. Accessed 14 May 2020.

4. Shah SK, Munoz AC. Multisystem inflammatory syndrome in children in COVID-19 pandemic. Indian J Pediatr. 2020. [published online ahead of print, $2020 \mathrm{Jul} \mathrm{3].} \mathrm{https://doi.org/10.1007/s12098-}$ 020-03440-7.

Publisher's Note Springer Nature remains neutral with regard to jurisdictional claims in published maps and institutional affiliations. 